\title{
Dental Caries in Geriatric Dentistry: An Update for Clinicians
}

\author{
Rapp $L^{1}$, Maret $D^{1}$, Diemer $F^{1}$ and Lacoste Ferré $M H^{2 *}$ \\ ${ }^{1} \mathrm{CHU}$ Toulouse Department of Conservative Dentistry and Endodontics, Toulouse III University, France \\ ${ }^{2}$ Toulouse Purpan Hospital, Garonne Hospital, France
}

*Corresponding author: Lacoste Ferré MH, Toulouse Purpan Hospital, Garonne Hospital, France

\section{Introduction}

Caries is a progressive infectious disease that, without treatment, leads to the destruction of the dental organ and can damage the surrounding tissues. According to the WHO, it is the third global scourge affecting all ages of life.

Over the past 40 years, prevention campaigns for children and adolescents have led to a decline in the prevalence of caries. The CAOD index for children aged 6 to 12 years decreased from 4.20 in 1987 to 1.23 in 2006 and there is an increase in the number of children who have no cavities [1].

The impact of these preventive actions is to preserve teeth throughout life. Although for a long time dental caries was the disease of children and young adults, and edentulousness that of elderly patients, the new generation of subjects over 65 years of age are increasingly dentulous, and are therefore more exposed to the risk of caries.

The risk of caries is an infectious risk which can have negative consequences on the health and quality of life of elderly patients: Development of remote infections (endocarditis), systemic disease imbalances (diabetes), aggravation of acute pathologies (aspiration pneumonia), discomfort, pain and difficulties chewing. This underlying infectious context has a greater impact on elderly patients who are the most vulnerable [2-9].

Access to care is a subject often mentioned in geriatrics. Annual dental check-ups are neglected in fragile patients and follow-up is no longer ensured on a regular basis. Access to dental care becomes difficult for the most dependent patients, especially those who are institutionalized. As a result, the first signs of fragility and dependence are accompanied by degradation in oral status with an increased development of gingival and carious pathologies $[10,11]$.

Therefore, current geriatric odontology is oriented towards conservative care. This means caring for and preventing caries in elderly patients who have retained their natural dentition, whatever their state of health and their degree of autonomy.

This article provides an update on the specific features of caries in the geriatric population as well as adapted preventive and curative strategies.

\section{Specific Features of Caries in Geriatrics}

In 2010, the report by the HAS (French High Health Authority) took into account studies on dental caries in the French population [1]. The report highlighted the fact that the proportion of adults that had at least one decayed tooth to be treated was $33-50 \%, 30-60 \%$ of the residents in long-term care facilities had conservative care needs and $44 \%$ had at least one decayed tooth. The study, which targeted people living at home, reported that $37 \%$ of these patients had caries.

In the United States, studies show a prevalence of caries of more than $40 \%$ in adults aged 75 years and older and the demand for conservative care is increasing [12-15].

The prevalence and incidence of caries in elderly patients are the highest among all age groups and increase with institutionalization. Patients in long-term care have more cavities than people living at home [16].

\section{Location and distribution}

In the elderly, caries mostly affects teeth roots. 
Coronal fissure caries is rarer, compared to other age groups. This can be explained by anatomical and physiological changes. On one hand, age-related periodontal atrophy exposes dental roots. On the other hand, there is physiological wear and tear and attrition blunts the coronal relief and modifies the points of interdental contact. Therefore, biofilm, food debris, is no longer retained at the coronal level but accumulates in interdental spaces [17].

The distribution within the oral cavity is characteristic [18]. The carious process begins at the vestibular and interproximal surfaces, at the level of the tooth neck [17]. In the most dependent patients, particularly in patients with cognitive disorders, caries increase due to a lack of follow-up and the absence of care. This leads to coronal fracture and the tooth is reduced to a root remnant.

\section{Clinical forms}

The mechanism of how caries occur is the same regardless of the age of the patient. It may be primary, initiated by an acid attack by bacteria directly on the exposed root surface or secondary, by infiltration of previously treated caries or a fixed prosthesis (crown, bridge).

Two clinical forms of root caries are found in geriatrics:

-Active caries: It is soft, chalky and yellow to light brown. They are close to the marginal gingiva and often covered with bacterial plaque. There may or may not be cavitation.

-Arrested caries is hard, smooth when probed, shiny and dark brown to black, located at a certain distance from the marginal gingiva.

Due to the localization in the root, the three dental tissues concerned are cementum, dentin and enamel. Enamel dissolves at a $\mathrm{pH}$ of 5.5, but cementum demineralizes at $\mathrm{a} \mathrm{pH}$ of 6.7. Cementum is more sensitive to the acidification of the oral environment. Cementum caries propagate twice as fast as coronal enamel caries [19].

\section{Risk factors}

Diet, bacterial plaque and host are the risk factors commonly described by the Selwitz diagram [20]. They are highly present in the geriatric population with a more significant and interdependent incidence.

Diet: Dietary habits and conditions change with age, even in autonomous patients. Masticatory efficiency decreases, taste changes, leading to foods being selected. Sarcopenia affects the masticatory muscles, causing weakness when masticating fibrous or hard food. The discrimination of sweet tastes is preserved but is gradually reduced for salty tastes. Therefore, the patient leans towards a soft diet, easier to chew but sticky, more tasty but rich in carbohydrate [21,22].

The frequency of food intake also changes with age. Snacking is more frequent throughout the day and the risk of caries increases more with the frequency of snacking than with sugar intake [23].

Nutrition is at the heart of management in institutionalized dependent patients, and must be adapted to the associated disorders such as dry mouth, swallowing disorders and muscle weakness. The adaptation of textures (soft, smooth or mixed), splitting meals in a context of dehydration and generalized fatigue modifies the mixing of food. Stagnation of the food bolus is observed in contact with the labial surfaces of the teeth, especially in the premolar-molar area.

Bacterial plaque or biofilm: At any age, the commensal flora present in the oral cavity is made up of different bacterial species. They can colonize dental surfaces and gums by agglomerating in the form of bacterial plaque, also called dental biofilm. They proliferate all the more as they are "fed" by the food residues deposited on teeth and gums after meals. Local pathologies (caries, gingivitis) can develop in case of selective proliferation of pathogenic species, depending on the permissiveness of the host.

In the elderly, the commensal flora is not as rich ( 245 bacterial species) as in young adults (500 species) [24]. In healthy elderly subjects, fusobacterium nucleatum polymorphum, few mutans streptococci and no lactobacilli and actinomyces are found $[25,26]$. Other bacteria are present on carious and pre-carious root sites; Pseudoramibacter alactolycus, propionibacterium, atopobium, olsenella, and selenomonas. In patients with rampant caries, there is a significant amount of mutans streptococci and lactobacilli and flora composed of bifidobacterium, veillonella, enterococci and candida albicans [27-29].

The number of pathogenic microorganisms increases with the acidity of the oral environment and a decrease in oral $\mathrm{pH}$ promotes a build-up of bacterial plaque.

To prevent the proliferation of bacterial plaque, daily oral and prosthetic hygiene are essential. They consist of removing bacterial plaque and food debris from the teeth, prostheses and mucous membranes. The mechanical action of brushing and the detergent action of toothpaste help to break up and remove biofilm from dental surfaces. Hygienic care also reduces oral acidity. Depending on their degree of autonomy and dexterity, elderly patients must be provided with appropriate hygienic care, or even assisted by caregivers [30].

Host: In the elderly, physiopathological gingival recessions expose the dental cervix and root surfaces. Anatomical modifications (widened interdental spaces, old restorations, isolated teeth) foster plaque retention and complicate hygienic care. 
The major risk is the reduction of salivary flow, very common in geriatrics. Mouth dryness is caused by physiological (atrophy of the salivary parenchyma) and hormonal factors as well as lack of stimulation. Salivary secretion is affected by general pathologies (dehydration, diabetes, rheumatoid arthritis) and the regular intake of antisialic medicines, very commonly prescribed in geriatrics. Hypoptyalism creates an acidic environment, which is favorable to the risk of caries. The composition of the saliva is modified in case of hypoptyalism with a decrease in immunoglobulin, lysozyme and mucin levels. Saliva decreases, becomes less fluid and prevents the natural self-cleaning of food debris. Mastication is disturbed and it becomes difficult to triturate dry, hard food. Salivary impregnation cannot be assured. All these elements weaken the moisturizing, lubricating, immunological and antibacterial role of the salivary flow $[24,31,32]$.

\section{Therapeutic Strategy}

In the elderly, all these conditions are favorable to the development of caries. Modification of the salivary flow, local conditions (presence of removable prostheses, gingival recessions), changes in eating habits and deficient daily hygiene practices are all factors that foster the formation of a biofilm (bacterial plaque) and increase the risk of caries. The entire therapeutic strategy must integrate all the risk factors even though actual control of all these factors is impossible. To be adapted and accessible, management must take into account local conditions as well as the general and cognitive status of the patient.

In geriatrics, according to the Si/Sta classification of Mount and Hume, caries are mainly encountered in site 3 (tooth neck) at all stages of progression. Sites 1 and 2 , dedicated to occlusal and proximal sites respectively, are less common in geriatrics [33]. This classification is of clinical interest in the treatment of carious lesions. It classifies lesions according to the cario-susceptible site and the stage of progression. This classification is chosen for its simplicity and its direct application.

Table 1 summarizes the 5 stages of the Si/Sta classification.

The therapeutic strategy must be preventive as well as curative and care must be simple and fast with techniques and materials adapted to the specific features of geriatrics. This is the whole point of minimal intervention dentistry, which was initially developed in pediatric odontology [34]. Stage 0 and stage 1 focus on preventive therapies, while stages 2,3 and 4 require curative care.

\section{Minimal Intervention Dentistry}

Minimal intervention dentistry enables the risk management of caries by a preventive and/or curative approach depending on the stage of lesions and using a technique adapted to geriatric patients [35].

The obvious and essential prerequisite is the introduction of adapted daily hygiene practices, more or less assisted according to the degree of autonomy of the patient [30]. Oral hygiene is the major component in the prevention of oral diseases, especially caries $[36,37]$.

Scaling should be done regularly to avoid periodontal disease.

\section{Treatment of stage 0 and 1 carious lesions}

The aim is to prevent carious lesions but also to interrupt or even re-mineralize early lesions. The preventive part of minimal intervention dentistry is based on the application of topical materials: Paste, gel and varnish [38,39].

Regular follow-up of the patient is essential in order to assess the stability or progression of caries. It is done every three months when the risk of caries is high and every 6 months for low risks.

Fluorine [38-41] inhibits the demineralization of dental surfaces and promotes their remineralization by the formation of fluorine-enriched hydroxyapatite.

At high concentrations it inhibits bacterial metabolism and therefore, the formation of bacterial plaque.

Fluorine concentration and the form depend on the risk of caries.

Patients at low risk use fluoride toothpaste with a concentration of 1,100 ppm for daily brushing.

If the risk of caries increases, a toothpaste with a higher fluorine concentration of 5,000 ppm should be used. For patients with a high risk of caries, it is supplemented by the application of a high-concentration $(22,600 \mathrm{ppm}-5 \%)$ fluoride varnish after dental surfaces are cleaned and dried. This application is renewed every 3 to 6 months. Their ease of implementation makes it possible to use them regardless of the patient's compliance.

Amorphous Calcium Phosphates are casein derivatives containing casein phosphopeptides and amor-

Table 1: Stages of evolution according to the classification of carious cervical lesions.

Stage 0 Colored cemento-dentin surface and more or less eroded.

Stage 1 Superficial cavitation which concerns the external third of the dentine, the amelo-dentinal junction is spared.

Stage 2 Cavitation of the middle third of the dentine, it extends in an apical and proximal direction.

Stage 3 Distinct cavitation of the internal third of the dentine, it extends towards the proximal surfaces.

Stage 4 Deep cavitation, creeping, extending all the way around the root canal. There is a risk of coronal fracture. 
phous calcium phosphate (CPP-ACP). This molecule binds to bacterial plaque and exposed dentin and interacts with hydrogen ions to form an electro-chemically neutral calcium-hydrogen-phosphate compound that can be incorporated by the enamel upon remineralization. PCP-ACPs are soluble in acidic media and re-balance the salivary $\mathrm{pH}$. The combination of fluoride with calcium phosphate enhances the result and allows deeper re-mineralization of dental structures than fluoride alone $[42,43]$. It is applied in the dental office after cleaning and drying of the dental surfaces or by the patient himself after each brushing. Amorphous Calcium Phosphates are used in addition to fluoride in patients with a high risk of caries.

Chlorhexidine is in the form of a $0.12 \%, 1 \%$ or $2 \%$ gel or varnish. Chlorhexidine reduces the risk of caries by decreasing bacterial concentration.

Its effectiveness is recognized especially in patients with poor oral hygiene and patients with dry mouth [4446].

In geriatrics we choose the gels or varnishes that adhere to the dental surfaces and do not require the compliance of the patient.

Chlorhexidine in addition to fluoride and amorphous calcium phosphates is for patients with bacterial plaqueinduced gingivitis and who are at a high risk for caries.

In patients with a high risk of caries, it is applied once a day after brushing for 4 weeks.

Inflammation and the risk of caries are then reevaluated.

In cases of dry mouth, a milder alcohol-free formula is chosen for the mucous membranes.
In a context of dry mouth, the application of local saliva substitutes improves hydration, lubrication and self-cleaning. The use of $\mathrm{BiNa}$ increases $\mathrm{pH}$, decreases acidity and therefore, improves a site that is conducive to the development of caries.

\section{Treatment of stage 2 and 3 lesions}

This concerns filling carious lesions while preserving dental tissues as much as possible. The curative component of minimally invasive dentistry is based on a less invasive cavity preparation technique and the use of cariostatic, bioactive and fluorinated fillers: Glass ionomer cements (GIC).

They are obtained by an acid-base reaction between glass fluoroaluminosilicate and polyalkenoic acid [47]. They allow deep cavities to be closed (pulp tolerance) and can be used under conditions unfavorable to bonding.

GIC exhibit intrinsic properties of adhesion to dentin and enamel and of bioactivity by releasing fluoride ions to the tooth and saliva $[48,49]$.

We distinguish:

- Traditional GICS

- GIC Modified by the addition of resin. They were introduced to compensate for the lack of resistance, to facilitate handling and improve the optical properties.

- Condensable or high viscosity GIC: Better mechanical strength, easy installation, significant fluorine release.

The protocol is summarized in the Table 2.

\section{Conclusion}

The preservation of dental capital is a real challenge

Table 2: Conservative treatment in geriatric dentistry.

\section{Beforehand}

Implementation of adapted \pm assisted hygienic care

Complete descaling

Stages of progression -clinical forms

\begin{tabular}{l|l} 
Stages 0 and 1 & Stages 2 and 3
\end{tabular}

Aim of treatment

To prevent the carious lesions

Interruption and/or remineralization of early lesions

To close carious lesions while preserving dental tissues as much as possible

\begin{tabular}{|c|c|c|}
\hline \multicolumn{2}{|l|}{ Preventive care } & Curative care \\
\hline \multicolumn{3}{|c|}{ Protocol-materials } \\
\hline $\begin{array}{l}\text { Brushing twice a day } \\
\text { Soft manual or electric } \\
\text { toothbrush }(20 / 100 e)+ \\
\text { Fluoride toothpaste } 1,100 \\
\text { ppm to } 5,000 \text { ppm }\end{array}$ & $\begin{array}{l}\text { Cleaning and drying teeth } \\
+ \text { Application of varnish, gel } \\
\text { or mouthwash Fluorine at } \\
22,600 \text { ppm or Amorphous } \\
\text { Calcium Phosphate or } \\
\text { Chlorhexidine: } 0.12 \% \\
\text { mouthwash or } 1 \text { or } 2 \% \text { gel }\end{array}$ & $\begin{array}{l}\text { Removal of infected dentin with a manual (excavator) or rotary } \\
\text { (low speed) instrument + Disinfection of the affected dentine with } \\
\text { chlorhexidine } 0.12 \%+\text { Isolation of the tooth from the saliva with } \\
\text { or without a surgical drape + Conditioning of the cavity with } 10 \% \\
\text { polyacrylic acid for } 10 \text { seconds, rinsing, gentle drying + Activation of } \\
\text { the capsule/mixing of the glass ionomer cement (GIC) + Filling with } \\
\text { the GIC, rapid sculpting }+/ \text { - photopolymerization }\end{array}$ \\
\hline \multicolumn{3}{|r|}{ 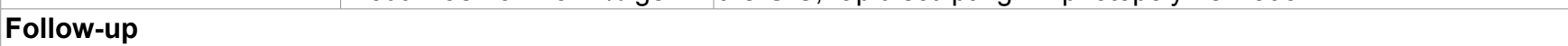 } \\
\hline Every day & $\begin{array}{l}\text { Follow-up in } 3 \text { months, then } \\
6 \text { months, then annually }\end{array}$ & Follow-up every 3 months, then every 6 month \\
\hline
\end{tabular}

Note: Stage 4-Objective = prevention of pain and infection (bite, abscess) - Treatment $=$ extraction(s) according to the patient's general health status. 
for modern geriatric dentistry. Minimal intervention dentistry is a technique of choice in the management of root caries. While its efficacy is unquestionable in children, this technique shows good results in the elderly. Based on prevention, remineralization of early lesions and minimal surgical preparation, it offers a realistic and adapted alternative to this population.

\section{Conflicts of Interest Statement}

The authors declare that they have no conflict of interest.

\section{Ethics Statement}

In accordance with the ethical standards.

\section{References}

1. Haute autorité de santé (2010) Stratégies de prévention de la carie dentaire.

2. Locker D, Clarke M, Payne B (2000) Self-perceived oral health status, psychological well-being, and life satisfaction in an older adult population. J Dental Res 79: 970-975.

3. Taylor GW, Manz MC, Borgnakke WS (2004) Diabetes, periodontal diseases, dental caries and tooth loss: A review of the literature. Compend Contin Educ Dent 25: 179-184.

4. Beck JD, Offenbacher S (2001) The association between periodontal disease and cardiovascular diseases: A state of the science review. Ann Periodontol 6: 9-15.

5. Sjogren $\mathrm{P}$, Nilsson $\mathrm{E}$, Forsell $\mathrm{M}$, Johansson $\mathrm{O}$, Hoogstraate $\mathrm{J}$ (2008) A systematic review of the preventive effect of oral hygiene on pneumonia and respiratory tract infection in elderly people in hospitals and nursing homes: Effect estimates and methodological quality of randomized controlled trials. J Am Geriatr Soc 56: 2124-2130.

6. Mattila KJ, Pussinen PJ, Paju S (2005) Dental infections and cardiovascular diseases: A review. J Periodontol 76: 2085-2088.

7. Boehm T, Scannapecio F (2007) The epidemiology, consequences and management of periodontal disease in older adults. J Am Dent Assoc 138: 26-33.

8. MacEntee MI (2007) Quality of life as an indicator of oral health in older people. J Am Dent Assoc 138: 47-52.

9. Scully C, Ettinger RL (2007) The influence of systemic diseases on oral health care in older adults. J Am Dent Assoc 138: 7-14.

10. MacEntee MI, Leeann R Donnelly (2000) Oral health and the frailty syndrome. Periodontol 2000 72: 135-141.

11. MacEntee MI (2015) Frail elder caries. Gerodontology 32: 81.

12. Lussi A, Maurer R, Zaugg D, Hotz P, Schaffner M (2001) Prévalence et facteurs de risque des caries radiculaires. Scheizer monatsschrift fur zahhnmedizin 4: 433-444.

13. Bagramian RA, Garcia-Godoy F, Volpe AR (2009) The global increase in dental caries. A pending public health crisis. Am J Dent 22: 3-8.

14. Dye BA, Tan S, Smith V, Lewis BG, Barker LK, et al. (2007) Trends in oral health status: United States, 1988-1994 and 1999-2004. Vital Health Stat 1-92.

15. Chiappelli F, Bauer J, Spackman S, Prolo P, Edgerton M, et al. (2001) Dental needs of the elderly in the 21st century. Gen Dent 50: 358-363.
16. Fani Anagnostou, Haysam Sawaf, Maya Feghali, JeanPierre Ouhayoun (2000) Cavité buccale et sénescence: Odontologie conservatrice, endodontique et restauratrice chez le sujet âgé. Elsevier Masson.

17. Shaker RE (2004) Diagnosis, prevention and treatment of root caries. Saudi Dental Journal 16: 84-92.

18. Gupta B, Marya C, Juneja V, Dahiya V (2006) Root caries: An aging problem. IJDS 5: 48-57.

19. Saunders RH, Meyerowitz C (2005) Dental caries in older adults. Dent Clin North Am 49: 293-308.

20. Selwitz RH, Ismail Al, Pitts NB (2007) Dental caries. Lancet 369: 51-59.

21. Dupuis V, Leonard A (2010) Odontologie du sujet âgé: Spécificité et prévention, Pratiques dentaires, Elsevier Masson, Paris, 192.

22. Folliguet M (2006) Prévention bucco-dentaire chez les personnes âgées. Direction générale de la santé SD2B.

23. Burt BA, Eklund SA, Morgan KJ, Larkin FE, Guire KE, et al. (1988) The effects of sugars intake and frequency of ingestion on dental caries increment in a three-year longitudinal study. J Dent Res 67: 1422-1429.

24. Lacoste Ferré $M H$, Hermabessière $S$, Jézéquel $F$, Rolland Y (2013) Oral ecosystem in elderly people. Geriatrie Psychologie Neuropsychiatrie du Vieillissement 11: 144-150.

25. Gendron R, Grenier D, Maheu-Robert L (2000) The oral cavity as a reservoir of bacterial pathogens for focal infections. Microbes Infect 2: 897-906.

26. Preza D, Olsen I, Willumsen T, Grinde B, Paster BJ (2009) Diversity and site-specificity of the oral microflora in the elderly. Eur J Clin Microbiol Infect Dis 28: 1033-1040.

27. Preza D, Olsen I, Aas JA, Willumsen T, Grinde B, et al. (2008) Bacterial profiles of root caries in elderly patients. J Clin Microbiol 46: 2015-2021.

28. Preza D, Olsen I, Willumsen T, Boches SK, Cotton SL, et al. (2009) Microarray analysis of the microflora of root caries in elderly. Eur J Clin Microbiol Infect Dis 28: 509-517.

29. Aparna A, Hegde MN, Shetty V (2013) Evaluation of microflora of root carious lesions in different age groups: $A$ microbiological study. EJGD 2: 130-133.

30. Marie-Hélène Lacoste-Ferre, Nicolas Saffon, Sarah Cousty, Jacqueline Berthaud, Philippe Cestac, et al. (2011) Les soins de bouche: de l'hygiène de base aux soins spécifiques. EM-consulte 10: 82-88.

31. Thomson WM, Chalmers JM, Spencer AJ, Slade GD (2000) Medication and dry mouth: Findings from a cohort study of older people. J Public Health Dent 60: 12-20.

32. Ship JA, Pillermer SR, Baum BJ (2002) Xerostomia and the geriatric patient. J Am Geriatr Soc 50: 535-543.

33. Lasfargues JJ, Louis JJ, Kaleka R (2008) Classifications des lésions carieuses. De Black au concept actuel par sites et stades. EM-consulte 1-19.

34. Frencken JE, van't Hof MA, Taifour D, Al-Zaher I (2007) Effectiveness of art and traditional amalgam approach in restoring single-surface cavities in posterior teeth of permanent dentitions in school children after 6.3 years. Community Dent Oral Epidemiol 35: 207-214.

35. Da Mata C, Allen PF, McKenna G, Cronin M, O'Mahony D, et al. (2015) Two-year survival of ART restorations placed in elderly patients: A randomised controlled clinical trial. J Dent 43: 405-411. 
36. Gati D, Vieira AR (2011) Elderly at greater risk for root caries: A look at the multifactorial risks with emphasis on genetics susceptibility. IJD 2011.

37. Da Mata C, McKenna G, Burke F M (2011) Caries and the older patient. Dent Update 38: 376-378.

38. Chalmers JM (2006) Minimal intervention dentistry: Part 1. Strategies for addressing the new caries challenge in older patients. J Can Dent Assoc 72: 427-433.

39. Chalmers JM (2006) Minimal intervention dentistry: Part 2. Strategies for addressing restorative challenges in older patients. J Can Dent Assoc 72: 435-440.

40. Ekstrand KR (2016) High fluoride dentifrices for elderly and vulnerable adults: Does it work and if so, then why? Caries Res 50: 15-21.

41. Donovan T, Swift Jr EJ (2008) Protocol for the prevention and management of root caries. JERD 20: 405-411.

42. Reynolds E, Walsh LJ (2005) Additional aids to the remineralisation of tooth structure. Knowledge books and software, 110-118.
43. Chi DL, Shyue C (2014) Managing caries risk in adults.

44. Autio-Gold $J(2008)$ The role of chlorhexidine in caries prevention. Oper Dent 33: 710-716.

45. Baca P, Clavero J, Baca AP, González-Rodríguez MP, Bravo M, et al. (2009) Effect of chlorhexidine-thymol varnish on root caries in a geriatric population: A randomized double-blind clinical trial. J Dent 37: 679-685.

46. Slot DE, Vaandrager NC, Van Loveren C, Van Palenstein Helderman WH, Van der Weijden GA (2011) The effect of chlorhexidine varnish on root caries: A systematic review. Caries res 45: 162-173.

47. Lasfargues JJ, Bonte E, Goldberg M, Jonas P, Tassery $H$ (1998) Ciments verres ionomères et matériaux hybrids. Odontologie.

48. Attal JP (2010) Les ciments verres ionomères (CVI). Société francophone de biomatériaux dentaires, Université médicale virtuelle francophone.

49. Amer RS, Kolker JL (2013) Restoration of root surface caries in vulnerable elderly patients: A review of the literature. Spec Care Dentist 33: 141-149. 